\title{
Bupropion in breast milk: an exposure assessment for potential treatment to prevent post-partum tobacco use
}

\author{
J S Haas, C P Kaplan, D Barenboim, P Jacob 3rd, N L Benowitz
}

Tobacco Control 2004;13:52-56

See end of article for authors' affiliations

Correspondence to: Jennifer S Haas, Brigham and Women's Hospital, 75 Francis Street, Boston 02115, USA; ;haas@ partners.org

Received 26 March 2003 Accepted 10 July 2003

\begin{abstract}
Objectives: To assess potential infant exposure to bupropion and its active metabolites in breast milk such as would occur during treatment to prevent post-partum relapse to tobacco use, and to compare the concentrations of bupropion in urine and saliva with plasma and breast milk.

Design and setting: Cohort study, outpatient clinical research centre.

Subjects: Ten healthy post-partum volunteers who agreed to take bupropion for seven days, pump and discard their breast milk, and have samples of breast milk, plasma, saliva, and urine analysed. Intervention: Bupropion $150 \mathrm{mg}$ a day for three days and then $300 \mathrm{mg}$ a day for four days.

Main outcome measures: Concentrations of bupropion and its active metabolites (hydroxybupropion, erythrohydrobupropion, threohydrobupropion) in breast milk, plasma, saliva, and urine. Determination of average infant exposure.

Results: The calculated average dosage of bupropion in breast milk was $6.75 \mu \mathrm{g} / \mathrm{kg} /$ day. Therefore, the average infant exposure is $0.14 \%$ of the standard adult dose of bupropion, corrected for the difference in body weight. Considering the sum of bupropion and its active metabolites, the average infant exposure is expected to be $2 \%$ of the standard maternal dose on a molar basis. The concentration of bupropion and its active metabolites in breast milk was not associated with age, body mass index, use of oral contraceptive pills, age of infant, or the frequency of breast feeding at the time the study was initiated. The coefficient of determination $\left(r^{2}\right)$ between the concentration of bupropion in breast milk and in urine was 0.77 $(p<0.01)$.

Conclusions: Bupropion and its active metabolites are present in the breast milk of lactating women. The concentrations of bupropion in breast milk and urine were highly correlated. These results indicate that the daily dose of bupropion and metabolites that would be delivered to an infant of a woman taking a therapeutic dose of bupropion is small. These results suggest that the effectiveness of bupropion to prevent post-partum relapse to tobacco use should be evaluated without excluding women who plan to breast feed.
\end{abstract}

igarette smoking is the leading cause of preventable morbidity and mortality for women in the USA. ${ }^{1}$ One

estimate suggests that $13 \%$ of all deaths among women are a direct result of tobacco use, and that smoking shortens a woman's life by an average of 15 years. ${ }^{2}$ Although tobacco use has been decreasing among women, a recent national report indicates that $24 \%$ of women still report current smoking. ${ }^{3}$ Pregnancy is a pivotal event of young adulthood for many women. Women are much more likely to quit smoking around the time of pregnancy than at any other. ${ }^{4}$ While the prevalence of smoking has also decreased among pregnant women, $12 \%$ of pregnant women report current smoking. ${ }^{3}$ Unfortunately, women who quit during pregnancy have extremely high rates of relapse during the months immediately following delivery. ${ }^{5-9}$ Behavioural interventions during pregnancy and the post-partum period have not been associated with an increase in post-partum tobacco abstinence. ${ }^{6} 1011$

Medications are typically avoided in lactating women because of the potential exposure of their infants. Approximately $65 \%$ of women breast feed in the early postpartum period, ${ }^{12}$ although the prevalence of breast feeding among women who quit smoking during pregnancy is probably lower than the general population. ${ }^{13}$ Few studies have quantified the exposure of infants to medications consumed by their breast feeding mothers. ${ }^{14-19}$ This practice leads women and their physicians to avoid medications, perhaps unnecessarily, or encourages women not to breast feed.
Bupropion is an effective therapy for smoking cessation and relapse prevention; it is as effective or more effective than nicotine replacement products. ${ }^{20-23}$ Bupropion is an atypical antidepressant that has both dopaminergic and noradrenergic activity. ${ }^{24}$ Bupropion is categorised for use in pregnancy by the US Food and Drug Administration as category B (that is, animal studies show no risk, or animal studies with minimal risk with no risk shown in humans). A slow release formulation became available in 1998, and this formulation is marketed for the treatment of smoking cessation. There are several reasons why bupropion may be particularly useful to prevent post-partum relapse, including mood stabilisation, decreased fatigue, decreased tobacco craving, and weight loss. ${ }^{20-22}$ To date, there is no literature examining the use of bupropion or other antidepressants as part of an intervention to prevent post-partum relapse to tobacco use. Bupropion, like other psychotropic medications, is lipid soluble and therefore secreted into breast milk. Information about the use of bupropion by lactating women is limited. Case reports note non-detectable plasma concentrations of bupropion and its metabolites in three infants of breast feeding mothers. ${ }^{18} 19$

This study was designed to measure the amount of bupropion and its active metabolites in the breast milk of women who are lactating but not breast feeding to ascertain whether this drug might be given safely to post-partum women, who are or may be breast feeding, to prevent postpartum relapse to tobacco use. We also examined concentrations of bupropion in urine and saliva compared to plasma 
and breast milk. If highly correlated, saliva or urine measurement would allow for less invasive monitoring of lactating women taking bupropion in the post partum period.

\section{METHODS}

\section{Subjects}

Ten healthy, paid volunteers were recruited through advertisements posted in clinic waiting rooms, and advertisements in parent periodicals. Women over the age of 18 years were eligible to participate if they were currently breast feeding at least three times per day and planned to discontinue breast feeding in the next few weeks. We excluded women who: (1) were currently using any psychoactive medications; (2) had current major depression, schizophrenia, or bipolar disorder; and (3) had a history of a seizure disorder, anorexia or bulimia, or intolerance to bupropion.

\section{Protocol}

Subjects were studied as outpatients at the clinical study centre at San Francisco General Hospital. An eligible woman was scheduled for an initial study visit at the time that she intended to stop breast feeding. At this visit eligibility was confirmed, informed consent was obtained, a health history was performed and blood pressure, weight and height were measured. At this visit, women were also instructed on the use of a breast pump, and provided with one if they did not already have one available. Women were instructed to stop breast feeding on that day and to begin pumping, and discarding, their breast milk at least three times per day. The following day, women were instructed to initiate bupropion SR $150 \mathrm{mg}$ orally once a day. Women were instructed to increase the dosage to $300 \mathrm{mg}$ a day after three days. Phone contact was maintained with women during this period to facilitate compliance. On the seventh day of the protocol, women came in for a second study visit. At this visit, a single sample of plasma, saliva, urine, and breast milk were each obtained. The initial $3 \mathrm{ml}$ of breast milk was obtained with the use of electric breast pump. Pill bottles were collected to ensure compliance with the medication dosing. We calculated an approximate time since the last dose ingestion by calculating the time elapsed between the start of the clinic visit and the scheduled time of the last pill ingestion.

\section{Analytical chemistry}

Measurement of bupropion and its active metabolites, hydroxybupropion, erythrohydrobupropion, and threohydrobupropion were quantitated in breast milk, plasma, saliva and urine using liquid chromatography-tandem mass spectrometry (LC-MS/MS). The method is similar to the one reported by Hsyu et al, but is capable of measuring the erythrohydrobupropion and threohydrobupropion individually. ${ }^{25}$ Deuterium labelled internal standards, which were synthesised in our laboratory, were used as internal standards. The lower limit of quantitation of the bupropion assay (LLOQ) is $1 \mathrm{ng} / \mathrm{ml}$. Samples were frozen and assayed in one batch at the completion of the study. There was no significant change in the concentration of bupropion and metabolites stored for one month in a freezer at $-20^{\circ} \mathrm{C}$. Quality control procedures that are appropriate for pharmacokinetic studies were utilised.

\section{Data analysis}

An average daily dose of bupropion and each of its active metabolites in breast milk was calculated. An average infant milk consumption of $0.15 \mathrm{l} / \mathrm{kg} /$ day was assumed. ${ }^{26}$ Since bupropion metabolites are pharmacologically active, ${ }^{24}$ the exposure of the infant to the sum of bupropion and its metabolites was estimated, and compared (on a molar basis) to the typical maternal weight-normalised exposure to bupropion. The Pearson correlation coefficients $(r)$ was used to calculate a coefficient of determination $\left(r^{2}\right)$ to compare the plasma, saliva, and urine concentrations of bupropion with breast milk concentration to determine whether saliva or urine measurement could be used (instead of plasma) to monitor bupropion concentrations in breast milk.

\section{RESULTS}

The median age of the 10 women who participated in this protocol was 29 years (range 22-37 years). Their median weight was $59.4 \mathrm{~kg}$ (range 54.1-95.5) and their median body

\begin{tabular}{|c|c|c|c|c|}
\hline & Breast milk & Plasma & Urine & Saliva \\
\hline Mean (SD) bupropion* & $45.2(49.5)$ & $25.0(24.6)$ & $1042.0(2139.0)$ & $68.5(131.4)$ \\
\hline Range & $4.2-168.3$ & $2.9-84.5$ & $32.7-7056.4$ & $3.2-439.0$ \\
\hline Mean (SD) hydroxybupropion & $104.6(62.2)$ & $940.2(697.7)$ & $2026.4(1873.0)$ & $184.5(143.9)$ \\
\hline Range & $9.0-242.1$ & $64.8-2672.8$ & $125.7-5032.8$ & $25.1-522.3$ \\
\hline Mean (SD) erythrohydrobupropion & $72.1(38.3)$ & $84.1(46.1)$ & $2396.2(1857.0)$ & $202.9(131.1)$ \\
\hline Range & $25.4-142.9$ & $19.9-196.5$ & $370.1-5972.1$ & $71.7-491.6$ \\
\hline Mean (SD) threohydrobupropion & $459.0(278.4)$ & $370.2(182.9)$ & $18791.3(16227.0)$ & $1229.5(794.1)$ \\
\hline Range & $192.7-1052.1$ & $121.4-746.6$ & $2484.5-45625.7$ & $469.3-3089.1$ \\
\hline
\end{tabular}

Table 2 Infant dose of bupropion and metabolites

\begin{tabular}{|c|c|c|c|c|c|}
\hline & $\begin{array}{l}\text { Mean milk } \\
\text { concentration }(\mathrm{ng} / \mathrm{ml})\end{array}$ & $\begin{array}{l}\text { Mean milk } \\
\text { concentration }(\mathrm{nM} / \mathrm{ml})\end{array}$ & $\begin{array}{l}\text { Infant dose } \\
(\mu \mathrm{g} / \mathrm{kg} / \text { day })\end{array}$ & $\begin{array}{l}\text { Infant dose } \\
\text { (nM/ } \mathrm{kg} / \text { day) }\end{array}$ & $\begin{array}{l}\text { Infant dose } ¥ \text { ( } \% \text { maternal } \\
\text { bupropion dose) }\end{array}$ \\
\hline Bupropion & 45 & 0.19 & 6.75 & 28.1 & 0.13 \\
\hline Hydroxybupropion & 105 & 0.41 & 15.75 & 61.5 & 0.30 \\
\hline Erythrohydrobupropion & 72 & 0.30 & 10.8 & 44.6 & 0.21 \\
\hline Threohydrobupropion & 459 & 1.90 & 68.85 & 284.5 & 1.37 \\
\hline Total & - & - & - & 418.7 & 2.01 \\
\hline
\end{tabular}

*Molecular weights: bupropion 240; hydroxybupropion 256; erythrohydrobupropion and threohydrobupropion 242.

tInfant dose based on breast milk concentration and infant consumption of $0.15 \mathrm{l} / \mathrm{kg} /$ day.

¥Maternal bupropion dose based on $300 \mathrm{mg} /$ day $=5 \mathrm{mg} / \mathrm{kg} /$ day $=20833 \mathrm{nM} / \mathrm{kg} /$ day

Metabolite percentages based on bupropion molar equivalents. 


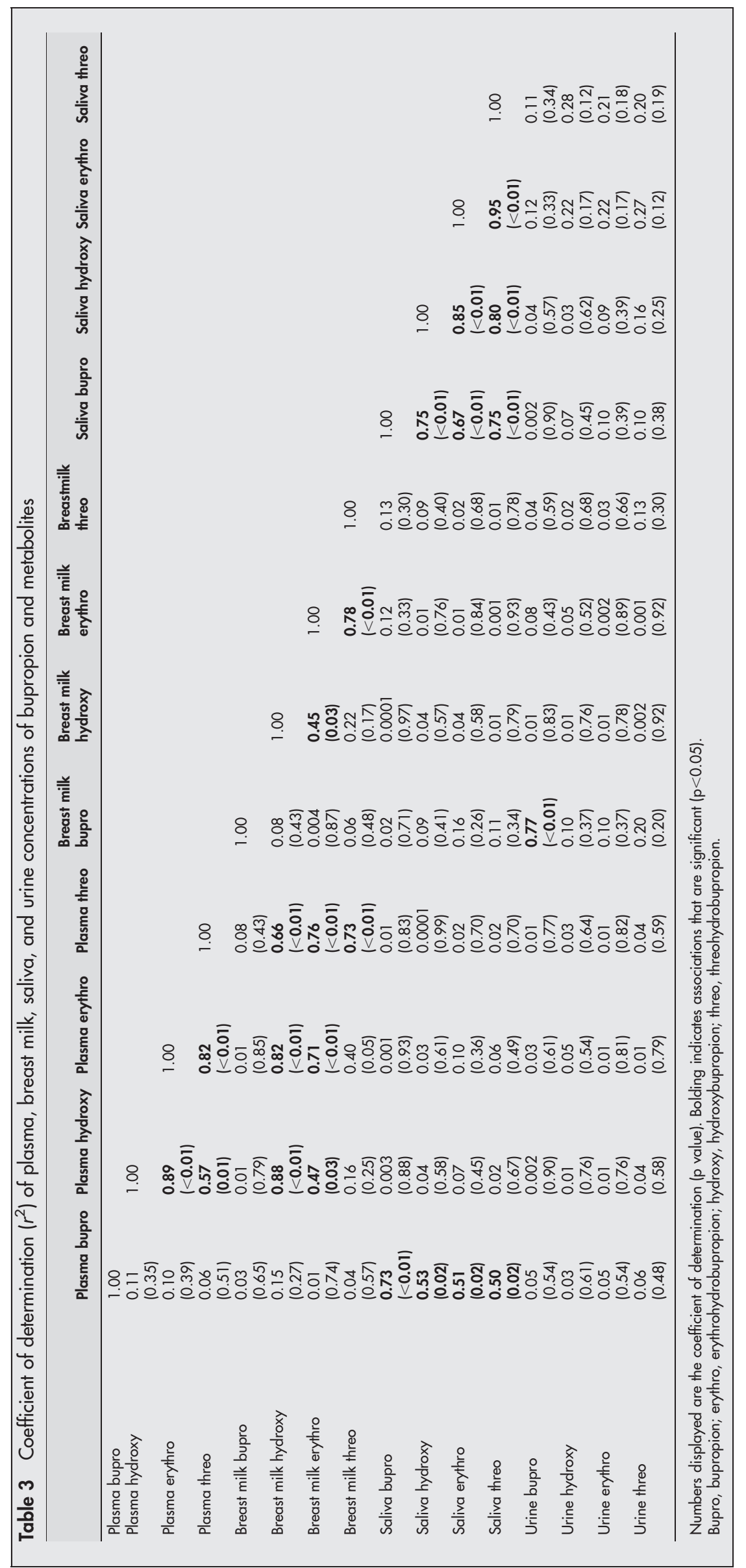


mass index was $25.3 \mathrm{~kg} / \mathrm{m}^{2}$ (range 20.9-38.4). At the time of participation, the average age of the infants of these women was 12.5 months. Half of the women were taking an oral contraceptive pill. No other medications were being used by any of the participants. The median number of hours since the last dose of bupropion was 2.5 hours (range 1-12 hours). The concentrations of bupropion and its active metabolites in breast milk, plasma, urine, and saliva are shown in table 1 . The average (SD) breast milk to plasma $(\mathrm{M} / \mathrm{P})$ bupropion ratio was 2.8 (3.7). The average M/P ratios of hydroxybupropion, erythrohydrobupropion, and threohydrobupropion were 0.1 (0.03), 0.9 (0.3), and $1.2(0.3)$, respectively. Since on average an infant drinks $0.15 \mathrm{l} / \mathrm{kg} /$ day, ${ }^{26}$ the calculated dosage of bupropion in breast milk is $6.75 \mu \mathrm{g} / \mathrm{kg} /$ day (table 2). The estimated daily infant dosages of the metabolites were: hydroxybupropion $15.75 \mu \mathrm{g} / \mathrm{kg} /$ day, erythrohydrobupropion $10.80 \mu \mathrm{g} / \mathrm{kg} / \mathrm{day}$, and threohydrobupropion $68.85 \mu \mathrm{g} / \mathrm{kg} /$ day.

The concentration of bupropion and its active metabolites in breast milk was not associated with age, body mass index, age of infant, use of oral contraceptive pills, or the frequency of breast feeding at the time the study was initiated.

The coefficient of determination between the concentration of bupropion in breast milk and in urine was $0.77(\mathrm{p}<0.01)$ (table 3 ). There was no significant association between saliva or plasma bupropion concentrations and the concentration of bupropion in breast milk, although there were significant correlations between plasma and saliva bupropion. No side effects were noted by any of the mothers.

\section{DISCUSSION}

Bupropion and its active metabolites are present in the breast milk of lactating women. These results indicate that the daily dose of bupropion and metabolites that would be delivered to an infant of a woman taking a therapeutic dose of bupropion is small. The estimated dose of bupropion taken up by the infant milk was less than $0.2 \%$ of the weight normalised dose of an adult woman. The major metabolites of bupropion are active, producing equal or weaker inhibition of neurotransmitter uptake compared to bupropion. ${ }^{24}$ Since the metabolites of bupropion have pharmacologic activity, the exposures of the metabolites should be considered as part of the infant drug exposure as well. If one conservatively assumes equimolar pharmacologic potency of the hydroxybupropion, erythrohydrobupropion, and threohydrobupropion metabolites to the parent bupropion, and assumes complete oral bioavailability in the infant, the total exposure to bupropion and metabolites would be $2 \%$ of the weight normalised maternal bupropion dose. This dose in the infant is lower than $10 \%$ of maternal dose that has been used as a guideline for drug safety during breast feeding. ${ }^{26}$ The failure to detect bupropion in three other breast fed infants whose mothers were taking bupropion in doses of 150-300 mg daily doses supports the idea that infants are exposed to a very low concentration of the drug. ${ }^{18} 19$

The coefficients of determination for breast milk with urine, saliva, and plasma concentrations of bupropion and its active metabolites were not high (with the exception of breast milk and urine bupropion concentrations). This suggests that future studies should not rely on these other body fluids as surrogate markers for breast milk.

The concentration of bupropion and its metabolites were measured in breast milk and in other body fluids at one point in time. Sampling at multiple times was not performed. Although the half life of bupropion is relatively long, there is an absorption peak after ingestion of the sustained release preparation, peaking at $1-4$ hours ${ }^{27}$ Most of our subjects had blood and milk samples taken around the time of the peak.

\section{What this paper adds}

Although women are much more likely to quit smoking around the time of pregnancy than at any other time, women who quit during pregnancy have extremely high rates of relapse during the months immediately following delivery. While bupropion has been shown to be effective in smoking cessation and delaying relapse, it has not been evaluated as a treatment to prevent post-partum relapse because of concerns over potential exposure by an infant who is breast fed. This study examines the potential exposure of an infant breast fed by a woman taking bupropion, and determined that infant exposure to bupropion and its active metabolites in breast milk is low. These results are important for designing clinical trials to prevent post-partum relapse that incorporate bupropion.

Therefore our estimates of exposure to bupropion are likely to be high; the actual exposure to bupropion would be even less than what we have estimated. Since the metabolites have longer half lives than bupropion and are generated slowly from bupropion, these concentrations are expected to be at or near steady state. Thus, the estimates of exposure to metabolites based on a single sample should be representative of the exposure over the day.

The women who participated had been breast feeding for an average of 12.5 months. It is possible that the milk composition after this length of breast feeding may be different than that in the immediate post-partum period. Although our results suggest that bupropion taken by a breast feeding mother should not present a concern for most infants, exposure may be greater for some infants-for example, premature infants.

Medications are typically avoided in lactating women because of the potential exposure of their infants. Few studies have quantified the true exposure of infants to medications consumed by their breast feeding mothers. ${ }^{14-17}$ This practice leads women and their physicians to avoid medications, perhaps unnecessarily, or encourages women not to breast feed.

Pregnant women have been extensively targeted for interventions to reduce prenatal tobacco use, primarily to protect the health of their unborn child. These efforts have been successful. Women are three times more likely to quit smoking during their first pregnancy and the year preceding this pregnancy than at any other time. ${ }^{4}$ Estimates suggest that approximately $30-50 \%$ of women who smoke spontaneously quit either immediately before or during pregnancy. ${ }^{28} 29$ Prenatal educational and behavioural interventions have been shown to increase cessation rates during pregnancy up to $50 \%{ }^{29-32}$ However, despite a high likelihood of quitting around the time of pregnancy, many women relapse following delivery. Several studies have demonstrated high rates of smoking relapse post-partum, ranging from 40$90 \%$ within six months. ${ }^{5-8} 28$ Bupropion has been shown to delay relapse to smoking in non-pregnant adults. ${ }^{22}$ Bupropion is generally safe and well tolerated, with relatively rare adverse effect..$^{21}$ Our results suggest that bupropion taken by a breast feeding mother should not present a concern for most infants. Particularly given the lack of success of behavioural therapies in promoting post-partum relapse, ${ }^{11}{ }^{33-37}$ the effectiveness of bupropion to prevent postpartum smoking relapse should be evaluated in clinical trials without excluding women who are or may be breast feeding. During such studies, however, it would be advisable to measure bupropion and metabolites in infants, to confirm that the exposure is as low as expected. 


\section{ACKNOWLEDGEMENTS}

The authors thank Lisa Yu for assay development. This work was supported by funding from the Tobacco-Related Disease Research Program (9IT-0192), and the US Public Health Service (DA 02277) from the National Institute on Drug Abuse. The study was carried out at the General Clinical Research Center at San Francisco General Hospital Medical Center with support of the Division of Research Resources, National Institute of Health (RR-00083).

\section{Authors' affiliations}

J S Haas, Brigham and Women's Hospital, Boston, Massachusetts, USA C P Kaplan, P Jacob 3rd, N L Benowitz, University of California, San Francisco, San Francisco, California, USA

D Barenboim, University of Chicago, Chicago, Illinois, USA

\section{REFERENCES}

1 Cigarette smoking among adults - United States, 2000. MMWR CDC Surveill Summ 2002;51(29):642-5.

2 Britton GA. A review of women and tobacco: have we come such a long way? J Obstet Gynecol Neonatal Nurs 1998;27:241-9.

3 Ebrahim SH, Merritt RK, Floyd RL. Smoking and women's health: opportunities to reduce the burden of smoking during pregnancy. Can Med Assoc J 2000;163:288-9

4 Brenner $\mathrm{H}$, Mielck A. The role of childbirth in smoking cessation. Prev Med 1993;22:225-36

5 Fingerhut LA, Kleinman JC, Kendrick JS. Smoking before, during, and after pregnancy. Am J Public Health 1990;80:541-4.

6 Mullen PD, Quinn VP, Ershoff DH. Maintenance of nonsmoking postpartum by women who stopped smoking during pregnancy. Am J Public Health 1990;80:992-4

7 McBride CM, Pirie PL. Postpartum smoking relapse. Addict Behav 1990;15:165-8.

8 McBride CM, Pirie PL, Curry SJ. Postpartum relapse to smoking: a prospective study. Health Educ Res 1992;7:381-90.

9 Carmichael SL, Ahluwalia IB. Correlates of postpartum smoking relapse. Results from the pregnancy risk assessment monitoring system (PRAMS). Am J Prev Med 2000;19:193-6.

10 McBride CM, Curry SJ, Lando HA, et al. Prevention of relapse in women who quit smoking during pregnancy. Am J Public Health 1999;89:706-11.

11 Ratner PA, Johnson JL, Bottorff JL, et al. Twelve-month follow-up of a smoking relapse prevention intervention for postpartum women. Addict Behav 2000;25:81-92.

12 Centers for Disease Control. Breastfeeding: Healthy People 2010 objectives for the nation, Vol. 2003, Centers for Disease Control, 1998.

13 Leung GM, Ho LM, Lam TH. Maternal, paternal and environmental tobacco smoking and breast feeding. Paediatr Perinat Epidemiol 2002;16:236-45.

14 Wisner KL, Perel JM, Findling RL. Antidepressant treatment during breastfeeding. Am J Psychiatry 1996;153:1132-7.

15 Gardiner SJ, Kirkpatrick CM, Begg EJ, et al. Transfer of metformin into human milk. Clin Pharmacol Ther 2003;73:71-7.

16 Hale TW, Kristensen JH, Hackett LP, et al. Transfer of metformin into human milk. Diabetologia 2002;45:1509-14
17 Stowe ZN, Hostetter AL, Owens MJ, et al. The pharmacokinetics of sertraline excretion into human breast milk: determinants of infant serum concentrations. J Clin Psychiatry 2003;64:73-80.

18 Briggs GG, Samson JH, Ambrose PJ, et al. Excretion of bupropion in breast milk. Ann Pharmacother 1993:27:431-3.

19 Baab SW, Peindl KS, Piontek CM, et al. Serum bupropion levels in 2 breastfeeding mother-infant pairs. J Clin Psychiatry 2002;63:910-1.

20 Hurt RD, Sachs DP, Glover ED, et al. A comparison of sustained-release bupropion and placebo for smoking cessation. N Engl J Med 1997:337:1195-202

21 Jorenby DE, Leischow SJ, Nides MA, et al. A controlled trial of sustainedrelease bupropion, a nicotine patch, or both for smoking cessation. N Engl J Med 1999;340:685-91.

22 Hays JT, Hurt RD, Rigotti NA, et al. Sustained-release bupropion for pharmacologic relapse prevention after smoking cessation. a randomized, controlled trial. Ann Intern Med 2001; 135:423-33.

23 Gonzales D, Bjornson W, Durcan MJ, et al. Effects of gender on relapse prevention in smokers treated with bupropion SR. Am J Prev Med 2002;22:234-9.

24 Ascher JA, Cole JO, Colin JN, et al. Bupropion: a review of its mechanism of antidepressant activity. J Clin Psychiatry 1995;56:395-401.

25 Hsyu PH, Singh A, Giargiari TD, et al. Pharmacokinetics of bupropion and its metabolites in cigarette smokers versus nonsmokers. J Clin Pharmacol 1997;37:737-43.

26 Bennett PN. Drugs and human lactation, 2nd ed. Amsterdam: Elsevier, 1996.

27 Johnston JA, Fiedler-Kelly J, Glover ED, et al. Relationship between drug exposure and the efficacy and safety of bupropion sustained release for smoking cessation. Nicotine and Tobacco Research 2001;3:131-40.

28 Quinn VP, Mullen PD, Ershoff DH. Women who stop smoking spontaneously prior to prenatal care and predictors of relapse before delivery. Addict Behav $1991 ; 16: 29-40$

29 Windsor RA, Cutter G, Morris J, et al. The effectiveness of smoking cessation methods for smokers in public health maternity clinics: a randomized trial. Am J Public Health 1985;75:1389-92.

30 Ershoff DH, Mullen PD, Quinn VP. A randomized trial of a serialized self-help smoking cessation program for pregnant women in an $\mathrm{HMO}$. Am J Public Health 1989:79:182-7.

31 Windsor RA, Lowe JB, Perkins LL, et al. Health education for pregnant smokers: its behavioral impact and cost benefit. Am J Public Health 1993:83:201-6.

32 Dolan-Mullen P, Ramirez G, Groff JY. A meta-analysis of randomized trials of prenatal smoking cessation interventions. Am J Obstet Gynecol 1994; 171:1328-34.

33 Wall MA, Severson HH, Andrews JA, et al. Pediatric office-based smoking intervention: impact on maternal smoking and relapse. Pediatrics 1995:96(4 Pt 1):622-8.

34 Lillington LM. AHCPR smoking cessation guideline goals and impact: examples from the nursing field. Tobacco Control 1997;6(suppl 1):S39-43.

35 Wakefield $\mathbf{M}$, Jones $\mathrm{W}$. Effects of a smoking cessation program for pregnant women and their partners attending a public hospital antenatal clinic. Austr N Z J Public Health 1998;22(3 suppl):313-20.

36 Lando HA, Valanis BG, Lichtenstein E, et al. Promoting smoking abstinence in pregnant and postpartum patients: a comparison of 2 approaches. Am J Manag Care 2001;7:685-93.

37 Van't Hof SM, Wall MA, Dowler DW, et al. Randomized controlled trial of a postpartum relapse prevention intervention. Tobacco Control 2000;9(suppl III):III64-6. 